\title{
The Economic Burden of Thromboembolic Events Among Patients with Immune-Mediated Diseases
}

\author{
Juliana Setyawan · Emma Billmyer · Fan Mu (D) - Andres Yarur • \\ Miriam L. Zichlin · Hongbo Yang • Nathaniel Downes • \\ Nassir Azimi • Vibeke Strand
}

Received: October 11, 2021 / Accepted: November 24, 2021 / Published online: December 14, 2021

(C) The Author(s) 2021

\begin{abstract}
Introduction: Thromboembolic events (TEs) are associated with considerable costs. However, there is a paucity of evidence quantifying the economic burden associated with TEs among patients with immune-mediated diseases (IMDs). Methods: This retrospective cohort study used the IBM MarketScan ${ }^{\circledR}$ Commercial and Medicare Supplemental Claims databases (2014-2018). Commercially insured adults with IMDs were classified into two cohorts based on diagnosis of TEs (deep vein thrombosis, pulmonary embolism, ischemic stroke, myocardial infarction). Patients in the TE cohort were matched on type of IMD, age, sex, and year of
\end{abstract}

J. Setyawan

Arena Pharmaceuticals, Inc., San Diego, CA, USA

E. Billmyer · F. Mu (ه) · M. L. Zichlin · H. Yang ·

N. Downes

Analysis Group Inc., 111 Huntington Avenue, 14th

Floor, Boston, MA 02199, USA

e-mail: Fan.Mu@analysisgroup.com

A. Yarur

Division of Gastroenterology and Hepatology,

Medical College of Wisconsin, Milwaukee, WI, USA

N. Azimi

Sharp Grossmont Hospital, La Mesa, CA, USA

V. Strand

Division of Immunology and Rheumatology,

Stanford University School of Medicine, Palo Alto,

CA, USA diagnosis to patients in the no TE cohort. In the TE cohort, the index date was the date of first TE following first IMD diagnosis. In the no TE cohort, the index date was assigned so the duration from first IMD diagnosis to index date matched the duration for the corresponding patient in the TE cohort. All-cause total healthcare costs were compared between cohorts in the 30-day and 1-year periods following the index date (inclusive). Unadjusted comparisons were conducted using Wilcoxon signed-rank tests. Adjusted results were estimated using generalized estimating equations with robust sandwich estimator.

Results: Overall, 9681 matched patients were included in each cohort (mean age 61.1 years; $63.7 \%$ female). The TE cohort had higher proportions of comorbidities than the no TE cohort (Charlson Comorbidity Index [1.5 vs. 0.9]; $p<0.0001)$. Adjusted all-cause total healthcare costs were significantly greater in the TE cohort versus no TE cohort in the 30-day and 1-year periods following the index date (cost difference: 30-day, $\$ 17,574$; 1-year, $\$ 36,459$; both $p<0.0001)$ and were driven by inpatient costs (cost difference: 30-day, \$14,864; 1-year, $\$ 23,360$; both $p<0.0001)$. TE-related healthcare costs were $\$ 15,955$ and $\$ 20,239$ in the 30-day and 1-year periods, respectively.

Conclusion: Among patients with IMDs, TEs are associated with substantial economic burden within 30-days and 1-year following the event. 
Keywords: Cost; Deep vein thrombosis; Economic burden; Immune-mediated diseases; Ischemic stroke; Myocardial infarction; Pulmonary embolism; Thromboembolic events

\section{Key Summary Points}

Why carry out this study?

Immune-mediated diseases (IMDs) are associated with an increased risk of thromboembolic events (TEs), which include venous events, such as deep vein thrombosis and pulmonary embolism, as well as arterial events, such as ischemic stroke and myocardial infarction.

IMDs and TEs are each associated with a substantial economic burden; however, limited evidence is available regarding the economic burden of TEs among patients with IMDs.

\section{What was learned from this study?}

Among adults with IMDs, the adjusted allcause total healthcare costs incurred over the 30-day and 1-year periods following a TE were significantly greater among patients who experienced TEs than among patients who did not experience TEs (cost difference: 30-day, $\$ 17,574$; 1-year, $\$ 36,459$; both $p<0.0001$ ); inpatient costs accounted for most of the cost differences.

Efforts aimed at reducing the risk of TEs among patients with IMDs may help lower the economic burden in this population.

\section{INTRODUCTION}

Immune-mediated diseases (IMDs) encompass a broad spectrum of unrelated conditions that involve dysregulation of the immune system leading to abnormal activation of inflammatory pathways [1]. IMDs can affect any organ in the body and typically result in debilitating symptoms that may be acute or chronic [2]. Over 100 conditions have been classified as IMDs; examples include rheumatoid arthritis, ankylosing spondylitis, psoriasis/psoriatic arthritis, systemic lupus erythematosus, atopic dermatitis, multiple sclerosis, and inflammatory bowel disease $[2,3]$. Although the prevalence of IMDs is reported to vary from $3 \%$ to $8 \%$ in Western regions (e.g., approximately 10-15 million Americans) [2, 4], these disabling conditions are among the leading causes of morbidity and mortality.

Patients with IMDs have increased risk of comorbidities, such as cardiovascular disease and thromboembolic events (TEs). TEs are potentially life-threatening events that include venous events, such as deep vein thrombosis (DVT) and pulmonary embolism (PE), as well as arterial events, such as ischemic stroke (IS) and myocardial infarction (MI) $[5,6]$. TEs carry a significant economic burden [5]. Conservative estimates of the costs of incident venous TE (VTE) to the United States (US) healthcare system are approximately $\$ 7-10$ billion each year [7]. TEs are also a strong predictor for unplanned readmissions in the US which can have a substantial economic impact on society [8].

While there have been studies on healthcare resource use and costs of TEs among the general population, for patients undergoing surgery and those diagnosed with cancer, less is known about the economic burden of TEs among patients with IMDs [9-11]. As the cost of TEs among patients with IMDs may differ from the costs of TEs in the general population or other patient populations, partly due to different comorbidity profiles, there is a need to quantify the economic burden in this patient population. To help address this knowledge gap, the current study quantified healthcare costs broadly among patients with IMDs who had evidence of a TE relative to patients with IMDs and no evidence of a TE. 


\section{METHODS}

\section{Data Source}

Data from the IBM MarketScan ${ }^{\circledR}$ Commercial and Medicare Supplemental Databases (2014-2018) were used for this study. These databases contain information on employerpaid encounters for active employees, early retirees, Consolidated Omnibus Budget Reconciliation Act continuees and dependents, as well as employer-sponsored Medicare supplemental healthcare encounters. Detailed information on patient demographic characteristics (e.g., age, sex, and geographic region), enrollment history, dates of service, and claims for medical (e.g., professional and institutional) and pharmacy services are also included in these databases.

\section{Compliance with Ethics Guidelines}

Institutional review board approval was not required for this study. The pre-existing, retrospective data from the IBM MarketScan ${ }^{\circledR}$ Commercial and Medicare Supplemental Databases are represented by IBM MarketScan to be fully de-identified in accordance with the Health Insurance Portability and Accountability Act. The data were provided under license agreement with IBM.

\section{Study Design and Sample Selection}

To be eligible for inclusion in this retrospective cohort study, patients were required to have at least two diagnoses (on separate dates) for an IMD, which included ankylosing spondylitis, atopic dermatitis, inflammatory bowel disease, multiple sclerosis, psoriasis, psoriatic arthritis, rheumatoid arthritis, and systemic lupus erythematosus. Patients diagnosed with a TE following an IMD diagnosis were matched to patients with no evidence of a TE at any time on the following characteristics: first IMD diagnosis, age at first IMD diagnosis, sex, and year of first IMD diagnosis. In this study, TEs included DVT, PE, IS, and MI. For patients with TE (i.e., TE cohort), the first diagnosis for a TE following the first diagnosis of an IMD was defined as the index date to help ensure that patients had an IMD at the time of the index TE. For patients in the cohort without TEs (i.e., no TE cohort), the index date was assigned so that the duration of time from the first IMD diagnosis to index date matched the duration from matched patients with TE. In this study, patients were required to have at least 6 months of continuous enrollment prior to the index date, at least one year of continuous enrollment following the index date, and be at least 18 years old on the index date. Patients in the TE cohort with no eligible matched controls were excluded from the analysis. For patients in the TE cohort with at least one eligible matched patient without a TE, one eligible patient was randomly selected.

\section{Study Measures and Outcomes}

\section{Patient Characteristics}

The following patient characteristics were assessed during the baseline period: demographics (age on index date, sex), type of IMD and non-IMD-related medications, and select comorbidities/conditions of interest.

\section{Healthcare Costs of TE}

Unadjusted all-cause total healthcare costs (medical and pharmacy) and cost differences between the TE and no TE cohorts were assessed during the 30-day and 1-year periods following the index date. In addition, models adjusted for the following: age on index date, sex (female), index year, healthcare plan type (capitation), baseline comorbidities/conditions of interest, baseline non-IMD medications, and baseline IMD medications. TE-related healthcare costs (i.e., cost of medical visits with diagnosis of TE) were also reported during the 30-day and 1-year periods following the index date.

\section{Statistical Analysis}

Study measures were described using means and standard deviations for continuous variables and counts and percentages for categorical variables. Unadjusted statistical comparisons for matched samples were conducted using Wilcoxon signed-rank tests for continuous 
variables and McNemar tests for categorical variables. The unadjusted results included mean (standard deviation) costs and differences in mean costs. Adjusted results included mean costs and $p$ values that were estimated and compared using generalized estimating equations with a robust sandwich estimator. Data processing and statistical analyses were performed using SAS Enterprise Guide version 7.15 (SAS Institute Inc., Cary, NC).

\section{RESULTS}

\section{Patient Characteristics}

After the sample selection criteria were applied, a total of 9681 matched patients were included in each cohort (Fig. 1). Across both cohorts, rheumatoid arthritis (31.6\%) was the most prevalent type of first IMD, followed by inflammatory bowel disease (19.5\%), psoriasis (16.5\%), systemic lupus erythematosus (12.4\%), multiple sclerosis (8.7\%), atopic dermatitis (7.5\%), psoriatic arthritis (3.1\%), and ankylosing spondylitis (1.5\%). The most common index event in the TE cohort was DVT (39.6\%) followed by IS $(31.8 \%)$, MI (18.9\%), and PE (14.3\%) (Table 1). In general, the TE cohort had higher rates of comorbidities than the no TE cohort, as reflected by the significant difference in the Charlson Comorbidity Index (1.5 vs. 0.9; $p<0.0001)$ and proportion of patients with comorbidities/conditions of interest (cardiovascular diseases, $68.0 \%$ vs. $52.8 \%$; type 2 diabetes, $22.8 \%$ vs. $14.1 \%$; both $p<0.0001$ ) (Table 1). The three most common medications in the TE cohort were glucocorticoids (35.6\%),

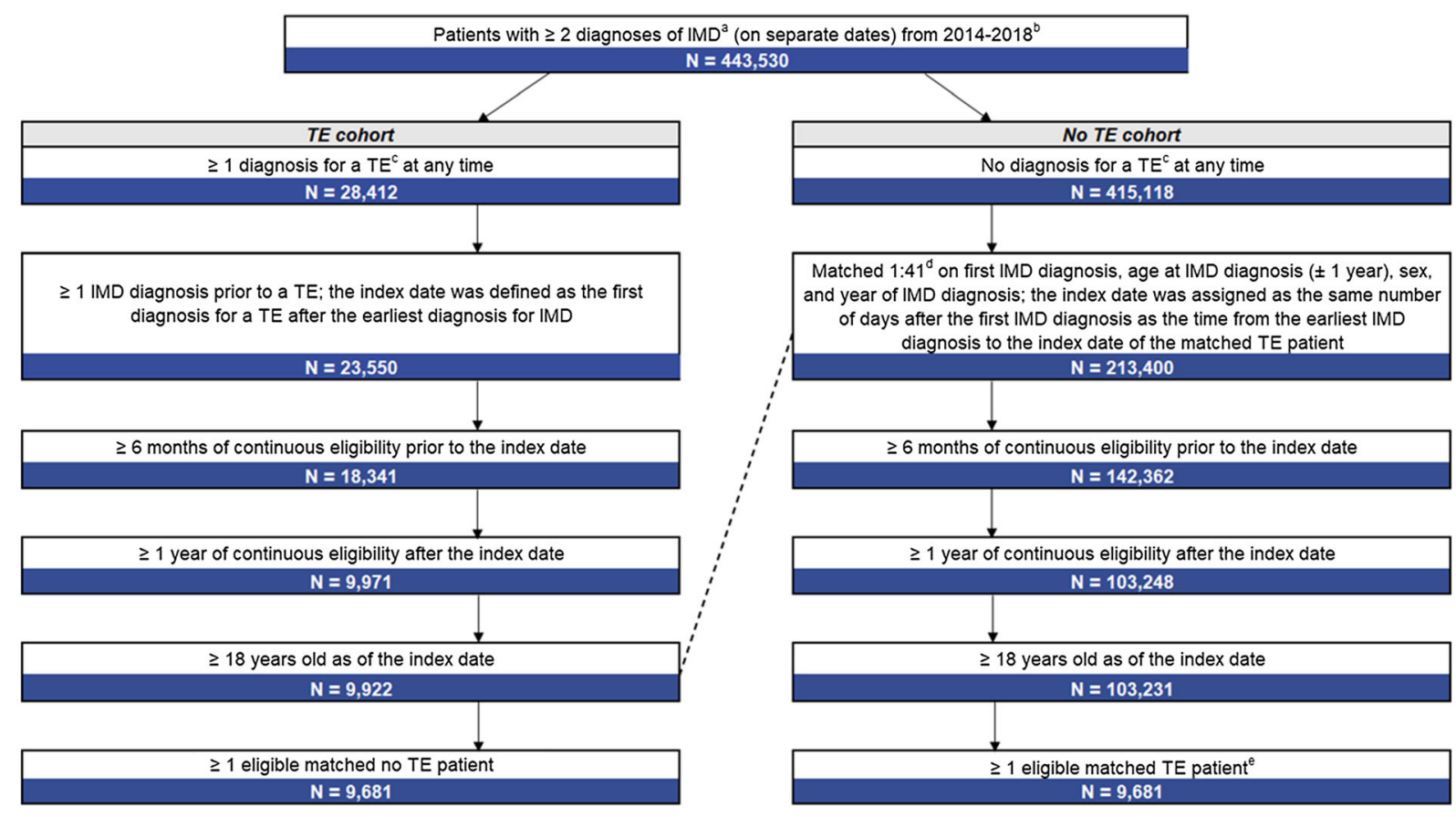

Fig. 1 Sample selection of patients with IMD with and without TEs. IMD immune-mediated disease, TE thromboembolic event. 'IMDs included ankylosing spondylitis, atopic dermatitis, inflammatory bowel disease, multiple sclerosis, psoriasis, psoriatic arthritis, rheumatoid arthritis, and systemic lupus erythematosus. ${ }^{\mathrm{b}}$ Qualifying diagnoses for IMDs were identified on the inpatient and/or outpatient services claims datasets. All patients were

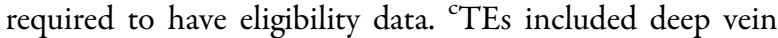
thrombosis, pulmonary embolism, ischemic stroke, and myocardial infarction. ${ }^{\mathrm{d}}$ Matching between the thromboembolic event cohort and no TE cohort was done with a 1:41 ratio to keep as many eligible patients with thromboembolic events as possible. ${ }^{\text {e}}$ For patients with $\mathrm{TE}$ with $\geq 1$ eligible matched patient with no TE, 1 patient with no TE was randomly selected 
Table 1 Demographics and clinical characteristics among patients with IMDs measured during the baseline period ${ }^{a}$

\begin{tabular}{|c|c|c|c|}
\hline & $\begin{array}{l}\text { TE cohort } \\
(n=9681)\end{array}$ & $\begin{array}{l}\text { No TE cohort } \\
(n=9681)\end{array}$ & $p$ value \\
\hline Age at index date (years), mean \pm SD & $61.1 \pm 14.6$ & $61.0 \pm 14.6$ & $<0.0001$ \\
\hline Female, $n(\%)$ & $6169(63.7)$ & $6169(63.7)$ & - \\
\hline \multicolumn{4}{|l|}{ Healthcare plan type, $n(\%)$} \\
\hline Plans with capitation & $958(9.9)$ & $1077(11.1)$ & 0.0049 \\
\hline Plans without capitation & $8616(89.0)$ & $8537(88.2)$ & 0.0715 \\
\hline Unknown & $107(1.1)$ & $67(0.7)$ & 0.0023 \\
\hline \multicolumn{4}{|l|}{ Index year, $n(\%)$} \\
\hline 2015 & $1704(17.6)$ & $1736(17.9)$ & 0.0845 \\
\hline 2016 & $3251(33.6)$ & $3234(33.4)$ & 0.5404 \\
\hline 2017 & $2625(27.1)$ & $2611(27.0)$ & 0.6245 \\
\hline 2018 & $2101(21.7)$ & $2100(21.7)$ & 0.9597 \\
\hline \multicolumn{4}{|l|}{ Immune-mediated disease ${ }^{\mathrm{b}}, n(\%)$} \\
\hline Ankylosing spondylitis & $179(1.8)$ & $161(1.7)$ & 0.0080 \\
\hline Atopic dermatitis & $775(8.0)$ & $753(7.8)$ & 0.0164 \\
\hline Inflammatory bowel disease & $1956(20.2)$ & $1932(20.0)$ & 0.0259 \\
\hline Multiple sclerosis & $863(8.9)$ & $854(8.8)$ & 0.1060 \\
\hline Psoriasis & $1750(18.1)$ & $1729(17.9)$ & 0.1707 \\
\hline Psoriatic arthritis & $435(4.5)$ & $410(4.2)$ & 0.1073 \\
\hline Rheumatoid arthritis & $3301(34.1)$ & $3201(33.1)$ & $<0.0001$ \\
\hline Systemic lupus erythematosus & $1292(13.3)$ & $1256(13.0)$ & 0.0033 \\
\hline TEs during baseline, $n(\%)$ & $1049(10.8)$ & - & - \\
\hline Deep vein thrombosis & $491(5.1)$ & - & - \\
\hline Pulmonary embolism & $289(3.0)$ & - & - \\
\hline Ischemic stroke & $337(3.5)$ & - & - \\
\hline Myocardial infarction & $119(1.2)$ & - & - \\
\hline TEs on index, $n(\%)$ & & & - \\
\hline Deep vein thrombosis & $3838(39.6)$ & - & - \\
\hline Pulmonary embolism & $1385(14.3)$ & - & - \\
\hline Ischemic stroke & $3080(31.8)$ & - & - \\
\hline Myocardial infarction & $1826(18.9)$ & - & - \\
\hline Charlson comorbidity index, mean $\pm S D$ & $1.5 \pm 1.7$ & $0.9 \pm 1.2$ & $<0.0001$ \\
\hline
\end{tabular}


Table 1 continued

\begin{tabular}{|c|c|c|c|}
\hline & $\begin{array}{l}\text { TE cohort } \\
(n=9681)\end{array}$ & $\begin{array}{l}\text { No TE cohort } \\
(n=9681)\end{array}$ & $p$ value \\
\hline \multicolumn{4}{|l|}{ Conditions/comorbidities of interest, $n$ (\%) } \\
\hline Cancer & $1300(13.4)$ & $861(8.9)$ & $<0.0001$ \\
\hline Cardiovascular diseases & $6584(68.0)$ & $5113(52.8)$ & $<0.0001$ \\
\hline Atherosclerosis & $1911(19.7)$ & $844(8.7)$ & $<0.0001$ \\
\hline Atrial fibrillation & $850(8.8)$ & $390(4.0)$ & $<0.0001$ \\
\hline Heart failure & $791(8.2)$ & $238(2.5)$ & $<0.0001$ \\
\hline Hyperlipidemia & $3878(40.1)$ & $3205(33.1)$ & $<0.0001$ \\
\hline Hypertension & $5354(55.3)$ & $3930(40.6)$ & $<0.0001$ \\
\hline Chronic kidney disease & $888(9.2)$ & $402(4.2)$ & $<0.0001$ \\
\hline Chronic obstructive pulmonary disease & $1059(10.9)$ & $469(4.8)$ & $<0.0001$ \\
\hline \multicolumn{4}{|l|}{ Diabetes } \\
\hline Type 1 & $315(3.3)$ & $138(1.4)$ & $<0.0001$ \\
\hline Type 2 & $2204(22.8)$ & $1364(14.1)$ & $<0.0001$ \\
\hline Fracture (hip or leg) & $149(1.5)$ & $50(0.5)$ & $<0.0001$ \\
\hline Peripheral vascular disease & $1135(11.7)$ & $513(5.3)$ & $<0.0001$ \\
\hline Pregnancy $^{c}$ & $86(1.4)$ & $65(1.1)$ & 0.0665 \\
\hline \multicolumn{4}{|l|}{ Common classes of medications, $n$ (\%) } \\
\hline \multicolumn{4}{|l|}{ Non-immunomodulatory } \\
\hline Anticoagulants & $1669(17.2)$ & $330(3.4)$ & $<0.0001$ \\
\hline Hormone replacement therapies ${ }^{c}$ & $345(5.6)$ & $397(6.4)$ & 0.0481 \\
\hline Testosterone replacement therapies ${ }^{c}$ & $110(3.1)$ & $102(2.9)$ & 0.5809 \\
\hline Oral contraceptives ${ }^{c}$ & $208(3.4)$ & $248(4.0)$ & 0.0386 \\
\hline \multicolumn{4}{|l|}{ Immunomodulatory } \\
\hline Biologics & $1006(10.4)$ & $1122(11.6)$ & 0.0038 \\
\hline TNF inhibitors & $766(7.9)$ & $908(9.4)$ & $<0.0001$ \\
\hline Interferon- $\beta 1 \mathrm{a}$ & $83(0.9)$ & $101(1.0)$ & 0.1521 \\
\hline Interleukin inhibitors & $114(1.2)$ & $78(0.8)$ & 0.0080 \\
\hline Other biologics & $62(0.6)$ & $50(0.5)$ & 0.2568 \\
\hline JAK inhibitors & $58(0.6)$ & $41(0.4)$ & 0.0843 \\
\hline Non-biologic immunomodulators & $2813(29.1)$ & $2936(30.3)$ & 0.0287 \\
\hline Methotrexate & $1117(11.5)$ & $1246(12.9)$ & 0.0017 \\
\hline S1P receptor modulators & $34(0.4)$ & $56(0.6)$ & 0.0151 \\
\hline
\end{tabular}


Table 1 continued

\begin{tabular}{llll}
\hline & $\begin{array}{l}\text { TE cohort } \\
(\boldsymbol{n}=\mathbf{9 6 8 1})\end{array}$ & $\begin{array}{l}\text { No TE cohort } \\
(\boldsymbol{n}=\mathbf{9 6 8 1})\end{array}$ & $\boldsymbol{p}$ value \\
\hline Other non-biologic immunomodulators & $1941(20.0)$ & $1978(20.4)$ & 0.4725 \\
5-Aminosalicyclic acid derivative agents & $1033(10.7)$ & $1059(10.9)$ & 0.4843 \\
Glucocorticoids & $3443(35.6)$ & $2412(24.9)$ & $<0.0001$ \\
NSAIDs & $2087(21.6)$ & $2014(20.8)$ & 0.1851 \\
\hline
\end{tabular}

${ }^{\text {a }}$ The baseline period was defined as the 1 -year period prior to the index date

IMD immune-mediated disease, JAK Janus kinase, NSAIDs nonsteroidal anti-inflammatory drugs, $S 1 P$ sphingosine 1-phosphate, $S D$ standard deviation, TEs thromboembolic events, TNF tumor necrosis factor

${ }^{b} \mathrm{IMDs}$ were reported at any time prior to the index date

${ }^{\mathrm{c}}$ The proportions of patients with pregnancy, hormone replacement therapies, and oral contraceptives were reported out of the total number of female patients in each group. The proportion of patients with testosterone replacement therapies was reported out of the total number of male patients in each group

Table 2 Unadjusted cost differences during the 30-day and 1-year periods among patients with IMDs

\begin{tabular}{|c|c|c|c|c|c|c|c|c|}
\hline & \multicolumn{4}{|c|}{ 30-day period } & \multicolumn{4}{|c|}{ 1-year period } \\
\hline & $\begin{array}{l}\text { TE cohort } \\
(n=9681)\end{array}$ & $\begin{array}{l}\text { No TE } \\
\text { cohort } \\
(n=9681)\end{array}$ & $\begin{array}{l}\text { Cost } \\
\text { difference }\end{array}$ & $p$ value & $\begin{array}{l}\text { TE } \\
\text { cohort }\end{array}$ & $\begin{array}{l}\text { No TE } \\
\text { cohort }\end{array}$ & $\begin{array}{l}\text { Cost } \\
\text { difference }\end{array}$ & $p$ value \\
\hline \multicolumn{9}{|c|}{ All-cause healthcare costs $(\$)^{\mathrm{a}, \mathrm{b}}$} \\
\hline Total costs & 19,681 & 1631 & 18,050 & $<0.0001$ & 58,474 & 19,824 & 38,650 & $<0.0001$ \\
\hline Medical costs & 18,640 & 777 & 17,863 & $<0.0001$ & 45,710 & 8956 & 36,753 & $<0.0001$ \\
\hline Inpatient & 15,812 & 184 & 15,628 & $<0.0001$ & 27,432 & 2387 & 25,046 & $<0.0001$ \\
\hline Outpatient & 1990 & 551 & 1440 & $<0.0001$ & 15,708 & 6079 & 9628 & $<0.0001$ \\
\hline $\begin{array}{l}\text { Emergency } \\
\text { department }\end{array}$ & 838 & 42 & 796 & $<0.0001$ & 2,570 & 490 & 2079 & $<0.0001$ \\
\hline Pharmacy costs & 1041 & 854 & 187 & $<0.0001$ & 12,764 & 10,867 & 1896 & $<0.0001$ \\
\hline
\end{tabular}

$I M D s$ immune-mediated diseases, TE thromboembolic event

${ }^{a}$ Unadjusted results include predicted costs and $p$ values, estimated using generalized estimating equations with a robust sandwich estimator

${ }^{\mathrm{b}}$ All costs were inflated to 2019 United States dollar

non-biologic immunomodulators (29.1\%), and nonsteroidal anti-inflammatory drugs (21.6\%). Use of anticoagulants was significantly higher in the TE cohort vs. the no TE cohort (17.2\% vs. $3.4 \% ; p<0.0001$ ) (Table 1).

\section{Healthcare Costs}

In both the unadjusted and adjusted analyses, the TE cohort incurred significantly greater total healthcare costs in the 30-day and 1-year periods following the index event versus the no TE cohort IMD (unadjusted cost difference: 30-day, 
Table 3 Adjusted cost differences during the 30-day and 1-year periods among patients with IMDs

\begin{tabular}{|c|c|c|c|c|c|c|c|c|}
\hline & \multicolumn{4}{|c|}{ 30-day period } & \multicolumn{4}{|c|}{ 1-year period } \\
\hline & $\begin{array}{l}\text { TE cohort } \\
(n=9681)\end{array}$ & $\begin{array}{l}\text { No TE } \\
\text { cohort } \\
(n=9681)\end{array}$ & $\begin{array}{l}\text { Cost } \\
\text { difference }\end{array}$ & $p$ value & $\begin{array}{l}\text { TE } \\
\text { cohort }\end{array}$ & $\begin{array}{l}\text { No TE } \\
\text { cohort }\end{array}$ & $\begin{array}{l}\text { Cost } \\
\text { difference }\end{array}$ & $p$ value \\
\hline \multicolumn{9}{|c|}{ All-cause healthcare costs $(\$)^{\mathrm{a}, \mathrm{b}}$} \\
\hline Total costs & 19,306 & 1731 & 17,574 & $<0.0001$ & 57,374 & 20,915 & 36,459 & $<0.0001$ \\
\hline Medical costs & 17,849 & 872 & 16,977 & $<0.0001$ & 42,742 & 9987 & 32,755 & $<0.0001$ \\
\hline Inpatient & 15,081 & 217 & 14,864 & $<0.0001$ & 25,945 & 2585 & 23,360 & $<0.0001$ \\
\hline Outpatient & 1923 & 576 & 1347 & $<0.0001$ & 14,666 & 6710 & 7956 & $<0.0001$ \\
\hline $\begin{array}{l}\text { Emergency } \\
\text { department }\end{array}$ & 854 & 42 & 812 & $<0.0001$ & 2383 & 547 & 1836 & $<0.0001$ \\
\hline Pharmacy costs & 1191 & 827 & 364 & $<0.0001$ & 14,066 & 10,909 & 3157 & $<0.0001$ \\
\hline
\end{tabular}

$I M D s$ immune-mediated disease, TE thromboembolic event

${ }^{a}$ Adjusted results include predicted costs and $p$ values, estimated using generalized estimating equations with a robust sandwich estimator. The adjusted models controlled for the following: cohort assignment, age at index date, sex (female), index year, healthcare plan type (capitation), baseline comorbidities/conditions of interest, baseline non-immune-mediating medications, and select baseline immune-mediating medications

${ }^{\mathrm{b}}$ All costs were inflated to 2019 United States dollar

$\$ 18,050$; 1 -year, $\$ 38,650$; adjusted cost difference: 30-day, $\$ 17,574$; 1 -year, $\$ 36,459$; all $p<0.0001$ ) (Tables 2 and 3). Overall, the adjusted cost differences in the 30-day and 1 -year periods were slightly less than the unadjusted cost differences but remained statistically significant after adjusting for potential confounders. The total healthcare cost differences were largely driven by differences in inpatient costs (unadjusted cost difference: 30-day, \$15,628; 1-year, \$25,046; adjusted cost difference: 30-day, \$14,864; 1-year, \$23,360; all $p<0.0001$ ) (Table 2). In the TE cohort, TE-related healthcare costs were $\$ 15,955$ and $\$ 20,239$ in the 30-day and 1-year periods, respectively.

\section{DISCUSSION}

This retrospective cohort study quantified the healthcare costs among adults with IMDs who had evidence of a TE relative to patients with IMDs and no evidence of a TE. Overall, our results showed that patients with IMDs with a
TE incurred greater total healthcare costs relative to those without a TE. Moreover, the main driver of this high-cost burden was inpatient costs. Taken together, results from this study have the potential to provide healthcare stakeholders with insights regarding decisions to prioritize efforts aimed at reducing the high economic burden of TEs among patients with IMDs.

To date, few studies have examined healthcare costs associated with TEs among patients with IMDs [7, 12]. As a result, insights regarding the cost burden in the IMD population have been limited. Previously, cost studies of TE have focused on specific subtypes of TE, IMDs, or the cost burden of TEs among the general population or in populations without IMDs [7, 12-14]. For example, a retrospective study published in 2019 based on data from 2003 to 2011 found that hospitalization costs among patients with systemic lupus erythematosus who experienced VTEs were greater by $\$ 25,400$ compared with those who did not experience VTEs [7]. The current study not only included patients with 
systemic lupus erythematosus but also with other IMDs, and found similar hospitalization costs. Other studies have shown that patients with TEs experience a significant economic burden compared with the general population. For example, one study estimated that annualized all-cause median costs were $\$ 17,512$ and $\$ 18,901$ for patients with DVTs and PEs, respectively, compared with $\$ 680$ in the control group (general population) [14]. Results from another study estimated that among patients with a VTE, the total annual healthcare costs for a VTE ranged from $\$ 7594$ to $\$ 16,644$ [13]. While the current study also found an increased economic burden among patients with TEs, the incremental economic burden of TE in our study among patients with IMDs is greater than the incremental burden previously reported in the general population. This difference can be possibly attributed to more severe TEs among IMD populations, higher downstream costs due to long-term medical needs after an acute TE, and/or a more severe comorbidity profile that further complicates the management of TEs, compared to the general population. Our findings extend the literature by quantifying the healthcare costs of TEs among patients with a range of IMDs. Additionally, this study assessed the overall burden of TE by including both venous and arterial events while previous studies have focused on the burden associated with specific subtypes of $\mathrm{TE}$, such as venous $\mathrm{TE}$ $[7,13,14]$. The current study did not assess the cost associated with each TE, but future studies could consider how costs may differ by subtype of TE.

Understanding the drivers of the increased healthcare costs can help stakeholders identify where to direct resources to mitigate costs. In this study, inpatient costs were the main driver behind the differences in healthcare costs between patients with IMDs with TEs and without TEs. The differences in inpatient costs accounted for $85 \%$ and $64 \%$ of the adjusted total cost difference in the 30-day and 1-year periods. This difference may be due to the acute TE on the index date and resulting inpatient stays. In this study, TE-related healthcare costs (i.e., cost of medical visits with diagnosis of TE) accounted for $88 \%$ and $52 \%$ of the unadjusted total cost difference in the 30-day and 1-year periods. It is important to note that the economic burden of TEs extends beyond the diagnosis and treatment of the initial event as costs of recurring TEs and associated longer-term effects can cumulatively add to the overall longterm cost burden, which is reflected in the 30-day vs. 1-year costs. Moreover, history of a TE is a significant risk factor for recurrent TEs $[15,16]$. For example, the risk of recurrence of VTEs has been reported to be $5-7 \%$ per year, which is 50 times higher than the risk in patients without a history of VTE [17]. Certain medications, such as glucocorticoids, nonsteroidal anti-inflammatory drugs, and Janus kinase inhibitors, have been reported to increase the risk of TE [5]. Given the substantial clinical and economic burden of TE among patients with IMDs, the risks of TEs among patients with IMDs should be carefully considered when optimizing treatment for this patient population. In addition, it may be helpful for further studies to evaluate ways to reduce the burden of TE after its occurrence among patients with an IMD.

\section{Limitations}

This study should be considered within the context of specific limitations. First, as with any observational claims-based study, databases may be vulnerable to errors in coding and/or data omission. Second, the primary function of claims data is to capture diagnostic and procedure codes for reimbursement. Therefore, the impact of omitted variables on costs associated with TE outcomes (e.g., body mass index, smoking, and immobility) could not be considered in the adjusted analysis as these measures are not collected in claims data. Moreover, other unmeasured and unobserved confounders could not be adjusted for, although this study adjusted for factors that were as comprehensive as was feasible from claims data. Finally, this analysis was conducted using a commercially insured population in the US. As a result, the findings may not be generalizable to other populations such as the Medicaid population, which may have different patient profiles than 
commercially insured patients, resulting in a cost estimate of the TE burden that could potentially be greater. Future studies using generalizable databases could provide insight into the economic burden among other segments of the population like Medicaid or uninsured/self-pay patients. As a result of these limitations, the results from this dataset may be a conservative estimate of the economic burden among patients with IMDs who experience TEs.

\section{CONCLUSIONS}

Among patients with IMDs, TEs are associated with substantial economic burden within the 30-day and 1-year periods after the event. Research focused on TE risk reduction among patients with IMDs may help to reduce their economic burden. Specifically, given the elevated risks of TEs and the high economic burden of TEs among patients with IMD, the risk of TEs should be carefully considered when optimizing treatment for this patient population.

\section{ACKNOWLEDGEMENTS}

Funding. Funding for this study and the Journal's Rapid Service Fee were provided by Arena Pharmaceuticals, Inc.

Medical Writing/Editorial Assistance. Editorial assistance in the preparation of this article was provided by Dr. Gloria DeWalt of Analysis Group, Inc. Support for this assistance was funded by Arena Pharmaceuticals, Inc.

Authorship. All named authors meet the International Committee of Medical Journal Editors (ICMJE) criteria for authorship for this article, take responsibility for the integrity of the work as a whole, and have given their approval for this version to be published.

Author Contributions. Juliana Setyawan, Emma Billmyer, Fan Mu, Miriam L. Zichlin, Hongbo Yang, Nathaniel Downes were involved in the study design and data acquisition. All authors were involved in data analysis and interpretation, drafting or revising the manuscript for intellectual content, take responsibility for the integrity of the work as a whole, and approved the final manuscript.

Disclosures. Emma Billmyer, Fan Mu, Miriam L. Zichlin, Hongbo Yang, and Nathaniel Downes are employees of Analysis Group Inc., which received consulting fees from Arena Pharmaceuticals, Inc. for the conduct of this study. Juliana Setyawan is an employee of Arena Pharmaceuticals, Inc. Andres Yarur serves as a paid consultant for Arena Pharmaceuticals, Prometheus Bioscience, and Takeda. Nassir Azimi is a member of the Delphi panel for Arena Pharmaceuticals; AstraZeneca - Speaker's Bureau; Daiichi Sankyo - Advisory Committee/ Board Member, Speaker's Bureau; Gilead Advisory Committee/Board Member, Speaker's Bureau; Janssen - Advisory Committee/Board Member, Speaker's Bureau. Vibeke Strand has received consultancy fees from AbbVie, Amgen, Arena Pharmaceuticals, AstraZeneca, Bayer, Blackrock, Bioventus, BMS, Boehringer Ingelheim, Celltrion, Concentric Analgesics, Crescendo/Myriad Genetics, EMD Serono, Equilium, Eupraxia, Flexion, Galapagos, Genentech/ Roche, Gilead, GSK, Horizon, Ichnos, Inmedix, Janssen, Kiniksa, Kypha, Lilly, Merck, MiMedx, MyoKardia, Novartis, Pfizer, Regeneron, Samsung, Samumed, Sandoz, Sanofi, Scipher, Servier, Setpoint, Tonix, UCB. Vibeke Strand has served on Advisory Boards for AbbVie, Amgen, AstraZeneca, Bayer, BMS, Boehringer Ingelheim, Celltrion, Crescendo, EMD Serono, Galapagos, Genentech/Roche, GSK, Horizon, Ichnos, Janssen, Lilly, Merck, Novartis, Pfizer, Regeneron, Samsung, Sandoz, Sanofi, UCB.

Compliance with Ethics Guidelines. Institutional review board approval was not required for this study. The pre-existing, retrospective data from the IBM MarketScan ${ }^{\circledR}$ Commercial and Medicare Supplemental Databases are represented by IBM MarketScan to be fully deidentified in accordance with the Health Insurance Portability and Accountability Act. The data were provided under license agreement with IBM. 
Data Availability. The datasets generated during the current study are not publicly available due to licensing agreement with IBM.

Open Access. This article is licensed under a Creative Commons Attribution-NonCommercial 4.0 International License, which permits any non-commercial use, sharing, adaptation, distribution and reproduction in any medium or format, as long as you give appropriate credit to the original author(s) and the source, provide a link to the Creative Commons licence, and indicate if changes were made. The images or other third party material in this article are included in the article's Creative Commons licence, unless indicated otherwise in a credit line to the material. If material is not included in the article's Creative Commons licence and your intended use is not permitted by statutory regulation or exceeds the permitted use, you will need to obtain permission directly from the copyright holder. To view a copy of this licence, visit http://creativecommons.org/licenses/bync/4.0/.

\section{REFERENCES}

1. Kuek A, Hazleman BL, Ostor AJ. Immune-mediated inflammatory diseases (IMIDs) and biologic therapy: a medical revolution. Postgrad Med J. 2007;83(978):251-60.

2. El-Gabalawy H, Guenther LC, Bernstein CN. Epidemiology of immune-mediated inflammatory diseases: incidence, prevalence, natural history, and comorbidities. J Rheumatol Suppl. 2010;85:2-10.

3. AARDA Inc. Autoimmune disease list. https://www. aarda.org/diseaselist/. Accessed 21 Jul 2021.

4. Agrawal M, Shah S, Patel A, et al. Changing epidemiology of immune-mediated inflammatory diseases in immigrants: a systematic review of population-based studies. J Autoimmun. 2019;105: 102303.

5. Setyawan J, Mu F, Yarur A, et al. Risk of thromboembolic events and associated risk factors, including treatments, in patients with immunemediated diseases. Clin Ther. 2021. https://doi.org/ 10.1016/j.clinthera.2021.06.008.
6. Hansson GK, Libby P, Tabas I. Inflammation and plaque vulnerability. J Intern Med. 2015;278(5): 483-93.

7. Kishore S, Jatwani S, Malhotra B, et al. Systemic lupus erythematosus is associated with a high risk of venous thromboembolism in hospitalized patients leading to poor outcomes and a higher cost: results from Nationwide Inpatient Sample database 2003-2011. ACR Open Rheumatol. 2019;1(3):194-200.

8. Amritphale A, Fonarow GC, Amritphale N, Omar B, Crook ED. All-cause unplanned readmissions in the United States. Insights from the Nationwide Readmission Database. Intern Med J. 2021. https://doi. org/10.1111/imj.15581.

9. Kourlaba G, Relakis J, Mylonas C, et al. The humanistic and economic burden of venous thromboembolism in cancer patients: a systematic review. Blood Coagul Fibrinolysis. 2015;26(1): $13-31$.

10. Sakon M, Maehara Y, Kobayashi T, et al. Economic burden of venous thromboembolism in patients undergoing major abdominal surgery. Value Health Reg Issues. 2015;6:73-9.

11. Khorana AA, McCrae K, Milentijevic D, et al. The risk of recurrent VTE and major bleeding in a commercially-insured population of cancer patients treated with anticoagulation. Am J Hematol. 2019;94(2):E58-61.

12. Yusuf HR, Hooper WC, Beckman MG, et al. Risk of venous thromboembolism among hospitalizations of adults with selected autoimmune diseases. J Thromb Thrombolysis. 2014;38(3):306-13.

13. Spyropoulos AC, Lin J. Direct medical costs of venous thromboembolism and subsequent hospital readmission rates: an administrative claims analysis from 30 managed care organizations. J Manag Care Pharm. 2007;13(6):475-86.

14. MacDougall DA, Feliu AL, Boccuzzi SJ, Lin J. Economic burden of deep-vein thrombosis, pulmonary embolism, and post-thrombotic syndrome. Am J Health Syst Pharm. 2006;63(20 Suppl 6):S5-15.

15. Samama MM. An epidemiologic study of risk factors for deep vein thrombosis in medical outpatients: the Sirius study. Arch Intern Med. 2000;160(22): 3415-20.

16. Alikhan R, Cohen AT, Combe S, et al. Risk factors for venous thromboembolism in hospitalized patients with acute medical illness: analysis of the MEDENOX study. Arch Intern Med. 2004;164(9): 963-8. 
17. Fahrni J, Husmann M, Gretener SB, Keo HH. Assessing the risk of recurrent venous thromboembolism-a practical approach. Vasc Health Risk Manag. 2015;11:451-9. 